\title{
Respiratory System Findings Time Point Reference
}

National Cancer Institute

\section{Source}

National Cancer Institute. Respiratory System Findings Time Point Reference. NCI

Thesaurus. Code C124030.

The point in time that acts as a fixed reference point to a respiratory system findings assessment. 